\title{
Inflammatory (reactive) hyperplastic conditions in puberty
}

\begin{abstract}
:
The gingiva is often the site of localize growth that are considered to be reactive rather than neoplastic in nature. Many of these lesions are difficult to be identified clinically and can only be identified by histological examination.Many types of localized reactive lesions occurring on the gingiva includes focal brous hyperplasia, pyogenic granuloma, peripheral giant cell granuloma and peripheral ossifying broma. Clinical reports of 12 and 13 year old girls with Pyogenic Granuloma and Peripheral ossifying fibroma are presented.

Purpose: The purpose of this study is to evaluate the treatment and pursuit process of the pyogenic granuloma and peripheral ossifying fibroma which has seen on 12 and 13 years old girl patient.
\end{abstract}

Key words: Focal brous hyperplasia, Pyogenic granuloma, Peripheral giant cell granuloma and Peripheral ossifying broma.

\section{Introduction:}

Many types of localized reactive lesions may occur on the gingiva including focal? brous hyperplasia, pyogenic granuloma, peripheral giant cell granuloma and peripheral ossifying? broma (POF).

Pyogenic Granuloma (PG). develop rapidly, reach full size, and then remain static for a period of time and later becomes fibrotic and indistinguishable from a fibroma.[1] Histopathologically, the selesions show thin parakeratinized stratified squamous epithelium which atrophic and ulcerated at places. The underlying connective tissue show delicate fibrocellular stroma with abundant endothelial lined blood capillaries which are engorged with red blood cells (RBCs) and dense chronic inflammatory cell infiltrate, chiefly of lymphocytes and plasmacells.

Peripheral ossifying Fibroma is a reactive soft tissue growth that is usually seen on the interdental papilla. It may be pedunculated or broad based, usually smoot surfaced and varies from pale pink to cherry red in color. It is believed to comprise about $9 \%$ of all gingival growths and to arise from

\begin{tabular}{|l|l|}
\hline \multicolumn{3}{|c|}{ Access this article online } \\
\hline \multirow{2}{*}{$\begin{array}{l}\text { Website: } \\
\text { www.ujds.in }\end{array}$} & Quick Response Code \\
\hline $\begin{array}{l}\text { DOI: } \\
\text { https://doi.org/10.21276/10.21276/ujds.2020.6.2.19 }\end{array}$ & \\
\hline
\end{tabular}

the gingival corium, periosteum and periodontal membrane. In this article we will discuss the two cases of reactive hyperplasia and how we can differentiate them.[2]

\section{Case Report-1}

A 12-year-old female child patient reported to the Department of Pediatric and Preventive Dentistry with a chief complaint of growth in the upper left back region of the mouth since[1] month. The growth was initially small but it gradually increased over a period of time. The patient had no deterioration in general health. She complained of bleeding on slightest touch but it was not associated with pain, sign of infection and lymphadenopathy. Oral examination revealed

\footnotetext{
${ }^{1}$ THAPA $V,{ }^{2}$ DHAWAN $P,{ }^{3}$ KHANDURI N, ${ }^{4}$ GUPTA B, ${ }^{5}$ GUPTA V, ${ }^{6}$ KAWOOS N

1,2,3 Seema Dental College \& Hospital, Rishikesh

${ }^{4,5}$ Oral and Maxillofacial Surgeon Consultant, New Delhi

${ }^{6}$ Private Practitioner, J\&K
}

Address for Correspondence: Dr. Nitin Khanduri Reader, Dept. of Paediatric and Preventive Dentistry, Seema Dental College \& Hospital, Rishikesh Email: nitinkhanduri658@gmail.com

Received : 31 July 2020, Published : 31 August 2020

How to cite this article: Thapa, V., Dhawan, P., Khanduri, N., \& Gupta, B. (2020). INFLAMMATORY (REACTIVE) HYPERPLASTIC CONDITIONS IN PUBERTY. UNIVERSITY JOURNAL OF DENTAL SCIENCES, 6(2): 109-11. 
peduncalated gingival enlargement of about $4 \times 3 \mathrm{~cm}$ in relation to ]11, 21] (Figure 1). The patient had poor oral hygiene. An intra oral periapical radiograph showed the absence of bone lysis. The differential diagnoses mentioned were fibroma / inflammatory epulis. Based on this diagnosis the treatment plan was decided. Initially oral prophylaxis of the patient was carried out. Following mechanical debridement and an antiseptic prescription, a marked improvement in gingival health was noted. The surgical phase involved the removal of the gingival growth which was carried out under local anaesthesia (Figure:2).Histological examination of the excised tissue revealed a connective tissue rich in granulation tissue and vessels, and an inflammatory invasion rich in polymorphonuclear neutrophils, which tends to indicate a diagnosis of pyogenic granuloma (Figure:3).

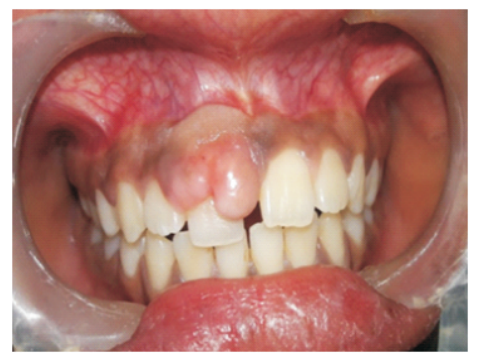

Figure 1: Intra oral picture showing soft tissue growth between maxillary central incisors.

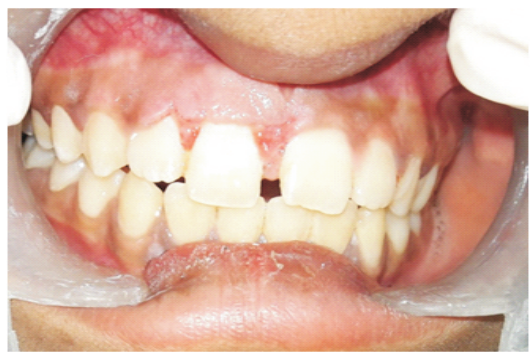

Figure 2: Post-operative

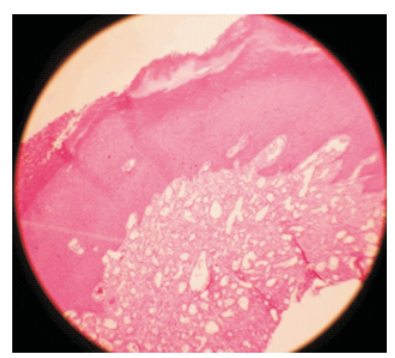

Figure 3:Histological image of lesion[10 $\times 10$ magnification]

\section{Case Report: 2}

A 13-year-old female patient reported to the Department of Pediatric and Preventive Dentistry complaining of soft tissue growth in the upper left back teeth region since 3 months. The swelling again was of smaller than peanut size when she which gradually increased. There was no history of trauma to the same region. The medical status was non-contributory, and family history was not significant. On intra-oral examination, a sessile gingival enlargement was found extending from distal aspect of maxillary first premolar to mesial aspect of maxillary first molar anterioposteriorly. It measured about $7 \mathrm{~mm} \times 8 \mathrm{~mm}$ diameter(Figure:4). The growth was ?rm in consistency, adhered to the palate, solitary and pinkish in color with no associated pain, and no bleeding while probing. Periapical radiographic examination revealed slight vertical bone loss between second maxillary premolar and first maxillary molar. The case was provisionally diagnosed as peripheral ossifying fibroma. At first oral prophylaxis was done. The growth was surgically excised under local anesthesia(Figure:5)The excised specimen was sent for histopathological examination and ? nally diagnosed as Peripheral ossifying Fibroma (Figure :6)

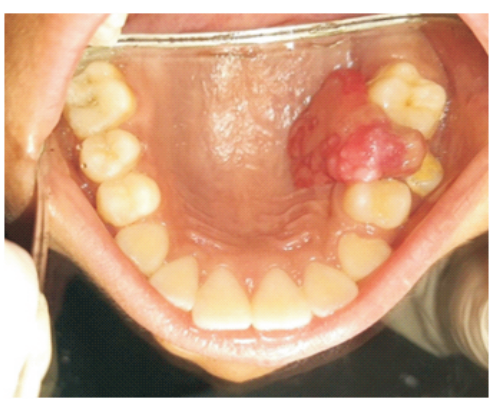

Figure 4: Intra oral picture showing soft tissue growth between 26 and 25 .

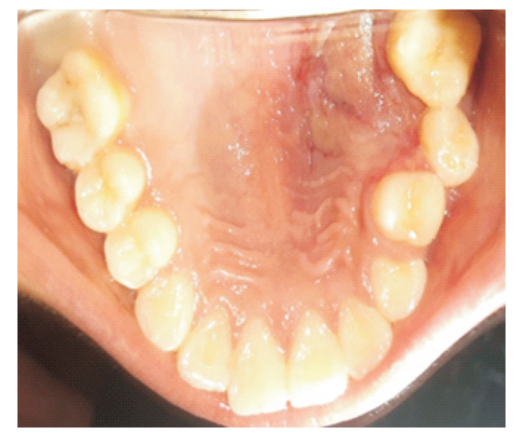

Figure 5: Post-operative

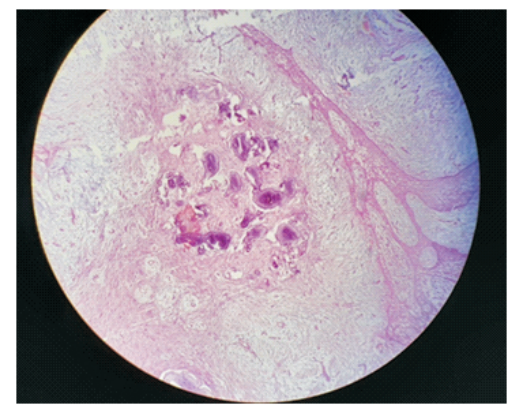

Figure 6: Histological image[10 $\times 10$ magnification] 


\section{Discussion:}

Higher prevalence of these lesions in women may show the role of hormonal factors as predisposing factors in the development of these lesions and it could reflect a greater attention in female patients to dental care. [3]

Oral Pyogenic Granuloma is a mucosal vascular hyperplasia affecting the tissues. It occurs due to respond of connective tissue to a minor injury or irritation.[4] Irritating factors may be dental calculi, poor oral hygiene, nonspecific infections, excessive restorations and buccal biting. Due to irritation the underlying fibrovascular connective tissue becomes hyperplastic and granulation tissue that cause formation of Pyogenic Granuloma is formed.[5] Due to high vascularity in the lesion, even a slight trauma can cause severe hemorrhages. Presence of obvious capillaries in newly-formed pyogenic granulomas and hyperplastic granulation tissue increases the probability of bleeding. Incidence of Pyogenic Granuloma among all reactive oral lesions is found to be between 26.8$32 \%$. Clinically, these lesions are formed as a single nodule or unpedunculated papule and with smooth or lobulated surfaces. Their dimensions can vary from some mm to some $\mathrm{cm}$. Clinical progression is slow, asymptomatic and painless but it can also show a rapid progression.[6]

Peripheral ossifying fibroma represents a common gingival growth, usually arising from the interdental papilla and representing up to $2 \%$ of all lesions that are biopsied.[7] In pediatric patient studies, the incidence of POFs in biopsied lesions ranged from $1 \%$ to $2 \% .8$ Eversoleet al.[9] stated that the constant irritation present during exfoliation of deciduous teeth and eruption of the permanent teeth may also result in an increased incidence of reactive lesions, which originate from the periodontal ligament. This hypothesis is based on the fact that POFs arise exclusively on the gingiva. Clinically, POFs present as exophytic, smooth surfaced pink or red nodular mass that is sessile or is less frequently seen on a pedicle.The recommended treatment of POF is a local surgical excision that extends to include the periosteum with submission for histopathological examination. Local resection is done with peripheral and deep margins including both the periodontal ligament and the a? ected periosteal component. In addition, elimination of local etiological factors such as plaque and tartar is required.[10]

\section{Reference:}

1. Effiom OA, Adeyemo WL, Soyele OO. Focal reactive lesions of the gingiva: an analysis of 314 cases at a tertiary health institution in Nigeria. Niger Med J 2011; 52(1):35-40.
2. Seifi S, Nosrati K. Prevalence of Oral Reactive Lesions and their Correlation with Clinico-pathologic Parameters. RJMS 2010; 17(76):36-44

3. Reddy V, Saxena S, Reddy M. Reactive hyperplastic lesions of the oral cavity: A ten year observational study on North Indian Population. J ClinExp Dent 2012; 4(3):e136-40.

4. Mathur LK, Bhalodi AP, Manohar B, Bhatia A, Rai N,Mathur A. Focal fibrous hyperplasia: a case report. Int J Dent Clin 2010; 2(4):6-7.

5. Kerr DA. Granuloma pyogenicum. Oral Surg Oral Med Oral Pathol 1951; 42: 158.

6. Ramirez. K, Bruce G, Carpenter W. Pyogenic granuloma: case report in a 9-yearold girl. General Dentistry. 2002;50:280-81.

7. Kumar SK, Ram S, Jorgensen MG, Shuler CF, Sedghizadeh PP. Multicentric peripheral ossifying fi broma. J Oral Sci 2006;48:239-43.

8. Das S, Das AK. A review of pediatric oral biopsies from a surgical pathology service in a dental school.Pediatr Dent 1993;15:208-11.

9. Eversole LR, Sabes WR, Rovin S. Fibrous dysplasia: a nosologic problem in the diagnosis of fi bro-osseous lesions of the jaws. J Oral Pathol 1972;1:189-220.

10. Trasad VA, Devarsa GM, Subba Reddy VV, Shashikiran ND. Peripheral ossifying fi broma in the maxillary arch. J Indian SocPedodPrev Dent 2011;29:255-9. 